\title{
Neoconstitucionalismo e Direitos Sociais
}

\author{
NEOCONSTITUCIONALISM AND SOCIAL RIGHTS
}

Mário Sérgio Falcão Maia ${ }^{(*)}$

\section{RESUMO}

No âmbito da teoria constitucional contemporânea, parte da doutrina trata de um novo paradigma. Esse novo referencial teórico - neoconstitucionalismo - , apesar de bastante citado, tem seus contornos ainda pouco conhecidos. Este trabalho verifica as consequências da aceitação desse novo modelo no que diz respeito aos direitos sociais. Parte da análise da doutrina em busca de uma definição possível do neoconstitucionalismo e das suas características básicas. Em seguida, parte para a análise dos aspectos referentes às mudanças necessárias na teoria dos direitos sociais, se se aceita esse novo paradigma. Esse cenário importa de maneira especial para os países periféricos, como o Brasil, que ainda não cumpriram de maneira satisfatória as promessas de modernidade positivadas constitucionalmente, ainda no início do século passado.

\section{Palavras-chave}

Direitos Sociais; Neoconstitucionalismo; Programático.

\section{Abstract}

In the field of the contemporary constitutionalism, part of the researches talk about the existence of a new model. This new theoretical base neoconstitutionalism - although widely cited, is still loosely defined. This paper verifies the consequences of the acceptance of this model in relation

(*) Mestre em Direitos Humanos pela Universidade Federal da Paraíba (UFPB); professor de Direito Constitucional da Faculdade Mater Christi. Advogado. E-mail: <mmaia22@yahoo.com>. Recebido em 15.4.09. Aprovado em 26.5.09. 
to the social rights. It starts with the analysis of the doctrine in search of a possible definition for 'neoconstitutionalism' and its basic characteristics. It follows with the analysis of the different aspects connected with the necessary changes in the theory of social rights. This scenario is especially important to peripheral countries like Brazil, which have not yet fulfilled the promises of modernity constitutionally guaranteed in the beginning of the last century.

\section{Keywords}

Neoconstitutionalism; Programmatic; Social Rights.

\section{INTRODUÇÃO}

No âmbito da teoria constitucional contemporânea, destacam-se os desenvolvimentos teóricos que vêm sendo agrupados sob o rótulo de "neoconstitucionalismo". O termo foi utilizado pela primeira vez pela doutrina italiana no fim da década de noventa do século passado e a sistematização em torno do tema se deu, principalmente, a partir de contribuições das doutrinas italiana e espanhola. Apesar da presença marcante no ambiente teórico, pode-se dizer que ainda inexiste uma conceituação totalmente aceita quando se trata de neoconstitucionalismo.

O objetivo desse trabalho é verificar as consequências da aceitação desse paradigma no que diz respeito à reformulação do modelo teórico dos direitos econômicos, sociais e culturais, considerando que é visível a falta de adequação do modelo ainda em vigor. Para essa visualização basta que se atente para a inadequação (às vezes, inexistência) de instrumentos jurídicos capazes de cobrar a efetividade desse grupo de direitos. Isso é verdade tanto no âmbito do direito internacional de proteção aos direitos humanos quanto no âmbito interno dos vários Estados Democráticos e Sociais de Direito.

Essa verificação se mostra fundamental, ainda, quando se constata que esse grupo de direitos caminha para o primeiro centenário da sua positivação constitucional, sem um mínimo de efetividade nos chamados países periféricos.

Assim, busca-se inicialmente um conceito possível de neoconstitucionalismo a partir da contribuição de diferentes autores. Em seguida, verificar-se-ão as consequências da aceitação desse paradigma no âmbito da reformulação teórica em torno de um grupo de direitos fundamentais específicos, a saber, os direitos econômicos, sociais e culturais. 


\section{EM BUSCA DE UM CONCEITO E DE CARACTERÍSTICAS BÁSICAS}

A partir do momento de reflexão necessária com o pós-guerra, o direito se depara com a necessidade de repensar toda a ideia de uma teoria "pura" e avalorativa nos moldes positivistas propostos até então. O modelo estatal resultante desse momento assume toda a carga axiológica já esboçada em época de constitucionalismo social e adiciona, como valor fundamental, a questão da democracia. Surge, então, o Estado Democrático de Direito fundado na dignidade da pessoa humana. É nesse ambiente de necessária reformulação teórica que começam a surgir as reflexões que mais tarde serão agrupadas sob o rótulo - ainda em construção — de neoconstitucionalismo.

A reflexão e desenvolvimento teórico em torno do neoconstitucionalismo dão-se, inicialmente, na Espanha e na Itália e, atualmente, estão presentes também - com bastante força - em vários países da América Latina, como o Brasil, a Argentina, a Colômbia e o México.

Como dito, o termo neoconstitucionalismo foi utilizado pela primeira vez, na Itália, por Susanna Pozzolo, em 1998, para "denominar um certo modo antijuspositivista de se aproximar o direito"(1). Desde então, vários autores, a partir de diferentes ambientes jurídicos, vêm tentando chegar a uma adequada conceitualização. Veja-se:

Sanchís(2) vai afirmar que o neoconstitucionalismo é uma nova "cultura jurídica", ou pelo menos uma "teoria do direito"; já Ahumada(3) diz que o termo neoconstitucionalismo está ligado ao novo paradigma do Estado Democrático de Direito e, ainda, que o termo faz referência a "un modelo de perfiles todavia confusos que ha obligado a la revisión de la filosofia del derecho".

Ainda sobre o tema, Figueroa(4) fala do neoconstitucionalismo como uma nova corrente ou um novo paradigma que escapa aos rótulos tradicionais e é capaz de superar a já esgotada dialética positivismo-jusnaturalismo. Ainda nesse sentido, destaca-se a opinião de Lopero(5), para quem a expressão neoconstitucionalismo vai ser usada para designar os grupos de mudanças visualizadas na prática e na compreensão dos ordenamentos jurídicos contemporâneos.

(1) DUARTE, Écio Oto Ramos; POZZOLO, Susanna. Neoconstitucionalismo e positivismo jurídico: as faces da teoria do Direito em tempos de interpretação moral da Constituição. São Paulo: Landy, 2006. p. 77.

(2) PRIETO SANCHÍS, Luis. El constitucionalismo de los derechos. In: CARBONELL, Miguel (Org.). Teoría del neoconstitucionalismo: ensaios escogidos. Madrid: Trotta, 2007.

(3) Apud BERNAL PULIDO, Carlos. Refutación y defensa del neoconstitucionalismo. In: CARBONELL, Miguel (Org.). Teoría del neoconstitucionalismo: ensaios escogidos. Madrid: Trotta, 2007. p. 289.

(4) Apud BERNAL PULIDO, Carlos. op. cit., p. 289-290.

(5) Apud MOREIRA, Eduardo Ribeiro. Neoconstitucionalismo: a invasão da Constituição. São Paulo: Método, 2008. p. 21. 
Assim, considerando esse referencial teórico, pode-se dizer que o neoconstitucionalismo representa um novo paradigma do direito formado a partir de diferentes propostas filosófico-teóricas ${ }^{(6)}$ e que tem como ponto de partida a reflexão pós-positivista, iniciada na segunda metade do século $X X$. Além disso, deve-se dizer que o eixo de ligação dessas diferentes propostas está no Estado Constitucional (Democrático) de Direito, que irá fornecer os elementos capazes de aglutinar diferentes pensamentos formulados a partir de diferentes culturas jurídicas.

Para que se possa ter uma ideia mais clara sobre quais desenvolvimentos podem ser agrupados sob esse rótulo, deve-se tratar de algumas características básicas, sempre no intuito de facilitar a compreensão do termo e delimitar o objeto de análise. Isso se mostra particularmente necessário se se considera a existência de desenvolvimentos teóricos pós-positivistas que não se afinam com o pensamento neoconstitucionalista, a exemplo da teoria estruturante de Müller $^{(7)}$.

Essas características básicas podem ser buscadas na observação do protagonismo reforçado dos direitos fundamentais na complexa sociedade contemporânea. Pode-se afirmar, então, que existem duas características básicas do pensamento neoconstitucionalista: o reconhecimento da existência de uma (1) Constituição material e (2) garantida ${ }^{(8)}$. A partir dessas duas características pode-se inferir que se entende o direito como um (3) conjunto composto de regras e princípios e que, devido a essa nova configuração, é necessário o uso da (4) ponderação como técnica de interpretação. Por fim, vê-se ainda que, com o reforço no protagonismo constitucional, pode-se dizer que (5) não existe um mundo político totalmente imune à influência constitucional.

\section{Ultrapassando o programático}

Considerando a materialidade das Constituições neoconstitucionalistas e, principalmente, a garantia destas, pode-se afirmar que não existe mais conteúdo meramente programático nesses textos normativos. Assim, os princípios, tanto quanto as regras, são juridicamente vinculantes.

No Brasil, essa afirmação se fundamenta no aprofundamento do trabalho teórico de autores como José Afonso da Silva ${ }^{(9)}$ e Paulo Bonavides ${ }^{(10)}$.

(6) Sobre a fragilidade da fronteira existente entre filosofia e teoria do direito em tempos pós-positivistas, ver RABENHORST, Eduardo. Filosofia ou teoria do direito? Problemata, João Pessoa, v. 2, n. 1, p. 77-94, 1998.

(7) MÜLLER, Friedrich. Teoria estruturante do direito. São Paulo: Ed. Revista dos Tribunais, 2008.

(8) PRIETO SANCHÍS, Luis. op. cit., p. 213.

(9) SILVA, José Afonso da. Aplicabilidade das normas constitucionais. 4. ed. São Paulo: Malheiros Ed., 2000.

(10) BONAVIDES, Paulo. Do Estado liberal ao Estado social. 7. ed. São Paulo: Malheiros Ed., 2004. 
Trata-se, em verdade, de afirmar a juridicidade das normas programáticas, buscando-se construir um referencial teórico capaz de afirmar uma eficácia positiva desse tipo normativo, ou seja, trata-se de ir além da eficácia negativa, já amplamente aceita no caso das normas programáticas, e buscar alternativas de cobrança de efetividade dos direitos sociais.

Assim, é possível, inclusive, se falar em direitos subjetivos decorrentes de uma interpretação e aplicação direta das normas programáticas, a exemplo do que acontece, já com relativa frequência no Brasil, quando o Judiciário garante o acesso a medicamento e/ou tratamento de saúde para indivíduos materialmente carentes ${ }^{(11)}$. Certamente que, para a caracterização dessa situação excepcional, depende-se sempre da análise do caso concreto.

Assim, não existe lei que escape ao controle de constitucionalidade, como não há o que possa ser considerado "questões políticas" apenas ${ }^{(12)}$. Essa afirmação ecoa de maneira especialmente profunda sobre a teoria dos direitos sociais fundamentais. Para se entender o porquê, deve-se voltar um pouco na história.

As Constituições do México (1917) e da Alemanha (1919) - no caso do Brasil, 1934 - tiveram o mérito de positivar, no topo do ordenamento jurídico-positivo, os chamados direitos sociais, cujo conteúdo-base é fruto das lutas empreendidas por aqueles que não se beneficiaram da liberdade formal do Estado Liberal clássico.

Portanto, esses direitos que foram gerados no século XIX e paridos no início do século XX dão início ao chamado Constitucionalismo Social, caracterizado pela positivação do compromisso firmado entre duas classes antagônicas: a burguesia e o proletariado. Essas Constituições são a certidão de nascimento do que se convencionou chamar de direitos de segunda geração, com base na lição de T. H. Marshal/(13).

Não se pode esquecer, no entanto, que o Constitucionalismo Social tem início em uma era de prestígio positivista que somente seria realmente abalado em meados do século XX. Assim, o que se tinha era uma situação de simbiose entre o positivismo jurídico e o Estado liberal — isso apesar da origem deste último ser ligada a toda uma tradição jusnaturalista e iluminista.

As normas de direitos sociais, caracterizadas pela fórmula de compromisso e pela redação aberta e de forte carga axiológica, não podiam prosperar em época de direito "puro"(14), em uma época de formalismo extremo.

(11) Recurso Extraordinário 271.286, por exemplo.

(12) GUASTINI, Ricardo. La constitucionalización del ordenamento jurídico. In: CARBONELL, Miguel. Neocontitucionalismo(s). Madrid: Trotta, 2005. p. 54.

(13) MARSHALL, T. H. Cidadania, classe social e status. Rio de Janeiro: Rumo, 1967.

(14) KELSEN, Hans. Teoria pura do direito. São Paulo: Martins Fontes, 1996. p. 1. 
Foi negada, então, a juridicidade dos direitos sociais constitucionalmente positivados e afirmada a sua programaticidade. As normas positivadoras do compromisso firmado entre a burguesia e o proletariado seriam apenas orientações dirigidas ao legislador, um catálogo de boas intenções.

Portanto, tendo como base o novo paradigma neoconstitucionalista, foi possível ultrapassar a programaticidade e afirmar a juridicidade das normas de direitos sociais, mediante o prestígio adquirido pelos princípios dentro da dinâmica do Estado Democrático de Direito. Em verdade, diz-se que atualmente os direitos fundamentais têm o caráter de princípios e que os princípios, por sua vez, são mandatos de otimização(15).

Desta forma, tendo como ponto de partida essa nova realidade, pode-se recorrer à jurisdição constitucional, que, valendo-se da ponderação no caso concreto, busca meios para a realização das promessas constitucionalmente positivadas.

\section{EM BUSCA DE UM MODELO DE DIREITOS SOCIAIS ADEQUADO}

Atualmente depara-se o direito com a necessária construção de um modelo de direitos sociais adequado ao constitucionalismo contemporâneo, ou seja, deve-se considerar a abertura dos textos que positivam os direitos sociais e, além disso, a passagem da teoria "abstrata" de direito liberal para a teoria aberta ao concreto dos direitos sociais. Assim, pode-se dizer que existe uma necessidade urgente de se criarem categorias adequadas à nossa realidade ${ }^{(16)}$ para se pensar os direitos sociais.

De fato, percebe-se que a abstração que caracterizava os direitos individuais expressos nas Constituições revolucionárias modernas não foi capaz de integrar a ideia de que os seres humanos são indivíduos concretos, situados na história(17), assim, a ideia de lei genérica e abstrata iluminista, que tinha como fundamento a suposição de uma sociedade homogênea, formada por homens "livres e iguais", não faz mais sentido quando se percebe os seres humanos e seus complexos e concretos problemas sociais.

Portanto, uma adequada teoria dos direitos sociais vai necessariamente ter que se preocupar com a análise dos casos concretos a partir dos quais serão entendidas as questões relativas a esse ser humano historicamente localizado, tornando-se relevante o pensar sobre a ponderação.

(15) ALEXY, Robert. Epílogo a la teoria de los derechos fundamentales. Madrid: Centro de Estudios, 2004. p. 13.

(16) Nesse sentido: COURTIS, Christian. Los derechos sociales en perspectiva. In: CARBONELL, Miguel (Org.). Teoría del neoconstitucionalismo: ensaios escogidos. Madrid: Trotta, 2007. p. 189.

(17) PECES-BARBA MARTÍNEZ, Gregorio. Lecciones de derechos fundamentales. Madrid: Dykinson, 2004. p. 133. 
$\mathrm{Na}$ esteira desse pensamento, Robert Alexy ${ }^{(18)}$ vai afirmar que os direitos sociais definitivos que o indivíduo possui só poderão ser conhecidos depois de um processo de ponderação. De acordo com o modelo proposto por esse autor, se, por um lado, não se pode dizer exatamente - de maneira abstrata, válida para todas as situações - quais são os direitos definitivos do indivíduo, por outro, se é capaz de identificar quais direitos esse indivíduo pode ter, considerando que os direitos definitivos só podem ser conhecidos depois da análise do caso concreto, após efetuada a ponderação.

Arango(19), baseado em uma perspectiva sul-americana, vai enfatizar o caráter de urgência da proteção dos direitos sociais em um quadro caracterizado ainda por várias omissões estatais absolutas. O autor, nesse contexto, vai identificar um direito (subjetivo) como sendo "uma posição normativa baseada em argumentos válidos e suficientes, cujo não reconhecimento injustificado causa dano àquele que é detentor do direito".

Pode-se inferir, desse modo, que é a ideia de necessidades básicas ${ }^{(20)}$ (em decorrência do princípio da dignidade humana), aliada à situação de urgência ocasionada, principalmente, por uma omissão por parte do Estado, que justifica a existência de direitos sociais subjetivos - mediante a análise de um caso concreto - e sua consequente justiciabilidade.

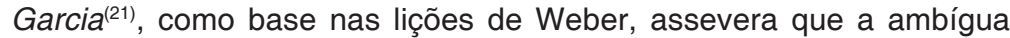
expressão "direitos sociais" pode ser enquadrada como direitos subjetivos, mandados constitucionais endereçados ao legislador ou princípios diretores e que, nessa ordem, essa escala vai indicar uma ordem decrescente em termos de densidade normativa e de potencial de exigibilidade. Porém, ainda que se trate de mandados constitucionais endereçados ao legislador ou princípios diretores, é possível que, à luz do caso concreto, origine-se um direito subjetivo, devido à força do princípio da dignidade humana.

Até aqui, tem-se visto que a ênfase teórica dá-se sobre os direitos sociais subjetivos e talvez seja esse o principal problema a ser enfrentado, quando se trata de pensar um modelo teórico adequado aos direitos sociais.

(18) ALEXY, Robert. Teoria de los derechos fundamentales. Madrid: Centro de Estudios Constitucionales, 1997. p. 494.

(19) ARANGO, Rodolfo. Direitos fundamentais sociais, justiça constitucional e democracia. In: MELLO, Cláudio Ari (Coord.). Os desafios dos direitos sociais. Porto Alegre: Livraria do Advogado, 2005. p. 93

(20) Aqui, prefere-se a expressão "necessidades básicas" a "mínimo existencial", em decorrência da lição de Potyara (POTYARA, A. P. Pereira. Necessidades humanas: subsídios à crítica dos mínimos sociais. 4. ed. São Paulo: Cortez, 2007. p. 26-27 e 36), que vai afirmar que, enquanto o básico "expressa algo fundamental, principal, primordial, que serve de base de sustentação indispensável e fecunda ao que a ela se acrescenta", o mínimo "nega o ‘ótimo' de atendimento". Portanto "o básico é a mola mestra que impulsiona a satisfação básica de necessidades em direção ao ótimo." Além disso, vai afirmar que as necessidades básicas "estão na base da concretização de direitos fundamentais por meio das políticas sociais".

(21) GARCIA, Emerson. O direito à educação e suas perspectivas de efetividade. In: MELLO, Cláudio Ari (Coord.). Os desafios dos direitos sociais. Porto Alegre: Livraria do Advogado, 2005. p. 981. 
É natural que assim seja, uma vez ser necessário que se ultrapasse o individualismo característico do direito liberal, cujas respostas não se aplicam aos questionamentos sociais atuais.

Esse individualismo está entranhado na ideia mesma de direito subjetivo, entendido como uma faculdade da pessoa, que na modernidade possibilitou uma análise do direito que privilegia o ponto de vista dos governados e não dos governantes - vai-se de Hobbes com seu Leviatã a Rousseau com sua vontade geral.

Deve-se lembrar, entretanto, que a ideia moderna de direito subjetivo só foi possível por meio da oposição deste ao direito objetivo já existente, ou seja, a partir do surgimento de uma dicotomia.

Assim, de acordo com a doutrina e jurisprudência tradicional, existe uma relação íntima e necessária entre direito subjetivo e direito objetivo. São as duas faces de uma mesma moeda. O direito é, ao mesmo tempo, um fenômeno objetivo, que não pertence a ninguém, e um fenômeno subjetivo que está nas mãos dos indivíduos. Essa dicotomia moderna foi possibilitada por uma ideia moderna de liberdade que de acordo com Ferraz $\mathrm{Jr}^{(22)}$,

[...] servirá à defesa da propriedade privada identificada com a riqueza, à defesa da economia de mercado livre e à concepção de Estado como um guardião (ameaçador) das liberdades fundamentais garantidas por um documento: a Constituição [liberal]. É com base nessa liberdade, que funciona como limite à atividade legiferante do Estado, que irá configurar-se a noção de direito subjetivo em oposição ao direito objetivo.

Destarte, não se pode estranhar a dificuldade encontrada, quando se trata de concretizar os direitos sociais. Atualmente, tenta-se construir um modelo de direitos sociais adequado ao modelo estatal e à complexidade contemporânea, visando a ultrapassar o paradigma liberal e buscando novas formas de se entender e construir o direito, capazes de ressaltar também o seu aspecto coletivo (difuso e coletivo stricto sensu). Nesse contexto, existe quem exclua até a possibilidade de se falar em direitos subjetivos sociais ${ }^{(23)}$.

É nesse sentido que ganha importância redobrada a dimensão objetiva dos direitos fundamentais, a qual irá tornar-se possível a partir da irradiação, já vista, da Constituição. No que diz respeito aos direitos sociais mais especificamente, é a partir do fortalecimento da dimensão objetiva que podem surgir alternativas de cobrança, principalmente contra a omissão estatal - total e parcial —, em grande parte responsável pela falta de efetividade dos direitos sociais.

(22) FERRAZ JR., Técio Sampaio. Introdução ao estudo do direito. 3. ed. São Paulo: Atlas, 1990. p. 144. (23) ATRIA, Fernando. Existem direitos sociais? In: MELLO, Cláudio Ari (Coord.). Os desafios dos direitos sociais. Porto Alegre: Livraria do Advogado, 2005. p. 9-46. 
Somente por meio desse reencontro contemporâneo com o direito objetivo, pode-se falar em uma justiciabilidade de direitos sociais que ultrapassa a lógica liberal e que permite a cobrança da realização das promessas constitucionais, positivadas desde o constitucionalismo social no início do século passado, a partir de uma lógica coletiva em que se tenta garantir o direito de um grupo (que não se beneficia da lógica liberal), ou, mais importante ainda, de toda a sociedade.

Como resultado desse reencontro tem-se, em verdade, a reconstrução da ideia de "era dos direitos (subjetivos)", com maior propriedade deve-se falar em uma era dos "direitos e deveres". Isso é verdade principalmente se se atenta para o fato de vários dos direitos fundamentais atuais não permitirem, inclusive, uma proteção calcada na defesa de um direito individual apenas. Veja-se, como exemplo, o direito a meio ambiente ecologicamente equilibrado (CF/88, art. 225).

Assim, o que se busca, a partir do fortalecimento da dimensão objetiva dos direitos sociais fundamentais, é "articular novas estratégias e abordagens para o enfrentamento dos mesmos problemas de justiça social que o capitalismo liberal não equacionou nem jamais equacionará"(24). Essa valorização do direito objetivo é particularmente importante nos Estados que nunca conseguiram desenvolver um Estado de Bem-estar nos moldes do europeu, pois ela vai permitir que se ultrapasse a programaticidade dos direitos sociais imposta pela ideologia liberal, que se escondia atrás de afirmações como a da "diferente estrutura normativa", dos "custos altos dos direitos sociais em oposição aos liberais", "reserva do possível", dentre outras. Vai, portanto, ampliar as possibilidades de luta pela concretização dos direitos sociais, permitindo que existam efeitos jurídicos concretos diretos, mesmo a partir de normas anteriormente consideradas programáticas, ou seja, aquelas que carecem de integração legislativa para a criação de direitos subjetivos fruíveis pelos seus titulares. Abre-se caminho, assim, para que a luta encampada pela sociedade não termine na positivação dos direitos, posto que essa positivação possa ser, muitas vezes, simbólica ${ }^{(25)}$, ou, como se diz no Brasil, "para inglês ver". Dessa forma, é possível se falar numa luta pela concretização do direito.

Não se trata, obviamente, de negar a importância dos direitos subjetivos ou de abrir mão dos direitos subjetivos sociais, mas sim de uma reflexão cuidadosa a respeito da dupla dimensão dos direitos fundamentais, com o intuito de potencializar as possibilidades de realização dos direitos sociais,

(24) SARMENTO, Daniel. A dimensão objetiva dos direitos fundamentais: fragmentos de uma teoria. In: SAMPAIO, José Adercio Leite. Jurisdição constitucional e direitos fundamentais. São Paulo: Del Rey, 2003. p. 253.

(25) O simbólico aqui tem um dos sentidos possíveis - o negativo - , como o explicitado por Marcelo Neves (NEVES, Marcelo. A constitucionalização simbólica. São Paulo: Acadêmica, 1994). 
fortalecendo seu caráter coletivo. Lembra-se então, com Canotilho(26), que quando se fala na fundamentação objetiva de uma norma positivadora de direitos fundamentais, está-se a ressaltar o seu significado para a coletividade, para o interesse público, para a vida comunitária.

Por fim, deve-se ressaltar, ainda, que aqui se trata dos direitos sociais a partir de uma perspectiva lata, ou seja, para além da proteção vinculada ao salário, que, muitas vezes, caracteriza esses direitos (veja-se o exemplo do direito do trabalho e suas garantias constitucionais e infraconstitucionais).

Trata-se, portanto, de entender os direitos sociais a partir de uma perspectiva ampla, não excludente, desvinculada da capacidade e da possibilidade dos indivíduos em conquistar o seu lugar no mercado de trabalho, como já ressaltado por Telles ${ }^{(27)}$.

Essa ênfase no social-coletivo justifica-se também pelo grau de amadurecimento já alcançado pelos direitos liberal-individuais. Estes, que, inicialmente, também foram criticados pelo seu alto grau de abstração, atualmente já estão estabelecidos na dogmática tradicional e possuem instrumentos jurídicos de cobrança efetivos (cite-se o habeas corpus, o mandado de segurança ou as próprias ações no âmbito do direito do trabalho).

Assim, fica claro que se busca, com a tese da dupla dimensão dos direitos fundamentais, reconhecer sua eficácia objetiva, que irá fundamentar a construção teórica capaz de fortalecer o conteúdo e ampliar o alcance dos direitos sociais, para além daquele já conhecido na tradicional concepção de direitos fundamentais como direitos subjetivos de defesa frente ao Estado, característico do modelo liberal de constitucionalismo.

\section{CONSIDERAÇÕES FINAIS}

Aceita a existência de um novo paradigma teórico-filosófico do direito que afirma a juridicidade das Constituições materiais surgidas principalmente a partir da década de setenta do século passado, faz-se necessária toda uma revisão teórica em torno do paradigma possível de direitos fundamentais.

Essa realidade reflete de maneira particularmente importante nos chamados países periféricos e mais especificamente no que diz respeito ao modelo de direitos econômicos, sociais e culturais. Isso é verdade se se considera que, apesar de positivados constitucionalmente no início do século passado, esses direitos representam uma promessa de modernidade que nunca foi minimamente garantida.

(26) CANOTILHO, J. J. Gomes. Direito constitucional e teoria da Constituição. 4. ed. Coimbra: Almedina, 2000. p. 1216.

(27) TELLES, Vera da Silva. Direitos sociais: afinal do que se trata? Belo Horizonte: UFMG, 2006. p. 94. 
Nesse contexto, tenta-se construir um modelo de direitos adequado a partir da crítica à modernidade liberal em dois de seus aspectos basilares: o individualismo e a abstração. Assim, fala-se em uma abertura do direito ao concreto, ao ser humano historicamente localizado. Busca-se, dessa forma, um modelo capaz de superar a igualdade formal - conquista do constitucionalismo no seu estágio inicial. Trata-se, em verdade, de uma crítica à teoria "geral" de direito, já que se permite uma abertura do direito à questão da justiça. Não uma justiça "mística", mas uma justiça concreta capaz de se materializar depois de um processo de ponderação.

Enfim, aceitar o paradigma neoconstitucionalista nos países periféricos significa buscar alternativas de cobrança pela efetividade dos direitos sociais, ultrapassando a ideia de programaticidade desses direitos. Significa, para utilizar-se de expressão já bastante conhecida, levar a sério esses direitos.

\section{REFERÊNCIAS BIBLIOGRÁFICAS}

ALEXY, Robert. Epílogo a la teoria de los derechos fundamentales. Madrid: Centro de Estudios, 2004.

Teoria de los derechos fundamentales. Madrid: Centro de Estudios Constitucionales, 1997.

ARANGO, Rodolfo. Direitos fundamentais sociais, justiça constitucional e democracia. In: MELLO, Cláudio Ari (Coord.). Os desafios dos direitos sociais. Porto Alegre: Livraria do Advogado, 2005.

ATRIA, Fernando. Existem direitos sociais? In: MELLO, Cláudio Ari (Coord.). Os desafios dos direitos sociais. Porto Alegre: Livraria do Advogado, 2005.

BERNAL PULIDO, Carlos. Refutación y defensa del neoconstitucionalismo. In: CARBONELL, Miguel (Org.). Teoría del neoconstitucionalismo: ensaios escogidos. Madrid: Trotta, 2007.

BONAVIDES, Paulo. Do Estado liberal ao Estado social. 7. ed. São Paulo: Malheiros Ed., 2004.

CANOTILHO, J. J. Gomes. Direito constitucional e teoria da Constituição. 4. ed. Coimbra: Almedina, 2000.

COURTIS, Christian. Los derechos sociales en perspectiva. In: CARBONELL, Miguel (Org.). Teoría del neoconstitucionalismo: ensaios escogidos. Madrid: Trotta, 2007.

DUARTE, Écio Oto Ramos; POZZOLO, Susanna. Neoconstitucionalismo e positivismo jurídico: as faces da teoria do direito em tempos de interpretação moral da Constituição. São Paulo: Landy, 2006. 
FERRAZ JR., Tércio Sampaio. Introdução ao estudo do direito. 3. ed. São Paulo: Atlas, 1990.

GARCIA, Emerson. O direito à educação e suas perspectivas de efetividade. In: MELLO, Cláudio Ari (Coord.). Os desafios dos direitos sociais. Porto Alegre: Livraria do Advogado, 2005.

GUASTINI, Ricardo. La constitucionalización del ordenamento jurídico. In: CARBONELL, Miguel. Neocontitucionalismo(s). Madrid: Trotta, 2005.

KELSEN, Hans. Teoria pura do direito. São Paulo: Martins Fontes, 1996.

MARSHALL, T. H. Cidadania, classe social e status. Rio de Janeiro: Rumo, 1967.

MOREIRA, Eduardo Ribeiro. Neoconstitucionalismo: a invasão da Constituição. São Paulo: Método, 2008.

MÜLLER, Friedrich. Teoria estruturante do direito. São Paulo: Ed. Revista dos Tribunais, 2008.

NEVES, Marcelo. A constitucionalização simbólica. São Paulo: Acadêmica, 1994.

PECES-BARBA MARTÍNEZ, Gregorio. Lecciones de derechos fundamentales. Madrid: Dykinson, 2004.

POTYARA, A. P. Pereira. Necessidades humanas: subsídios à crítica dos mínimos sociais. 4. ed. São Paulo: Cortez, 2007.

PRIETO SANCHÍS, Luis. El constitucionalismo de los derechos. In: CARBONELL, Miguel (Org.). Teoría del neoconstitucionalismo: ensaios escogidos. Madrid: Trotta, 2007.

RABENHORST, Eduardo. Filosofia ou teoria do direito? Problemata, João Pessoa, v. 2, n. 1, p. 77-94, 1998.

SARMENTO, Daniel. A dimensão objetiva dos direitos fundamentais: fragmentos de uma teoria. In: SAMPAIO, José Adercio Leite. Jurisdição constitucional e direitos fundamentais. São Paulo: Del Rey, 2003.

SILVA, José Afonso da. Aplicabilidade das normas constitucionais. 4. ed. São Paulo: Malheiros Ed., 2000.

TELLES, Vera da Silva. Direitos sociais: afinal do que se trata? Belo Horizonte: UFMG, 2006. 